\title{
Identification of a small molecule Cyclophilin D inhibitor for rescuing $A \beta$-mediated mitochondrial dysfunction
}

Koteswara Rao Valasani ${ }^{\dagger \ddagger}$, Qinru Sun ${ }^{\dagger \ddagger \S}$, Du Fang ${ }^{\dagger}$, Zhihua Zhang ${ }^{\dagger}$, Qing Yu ${ }^{\dagger}$, Yaopeng Guo ${ }^{\dagger}$, Jianping $\mathrm{Li}^{\dagger}$, Anuradha Roy ${ }^{\#}$, and Shirley ShiDu Yan ${ }^{\dagger *}$

†Department of Pharmacology \& Toxicology and Higuchi Bioscience Center, School of Pharmacy, University of Kansas, Lawrence, KS 66047 (USA) ${ }^{\S}$ College of Medicine and Forensics, Xi'an Jiaotong University Health Science Center, Xi'an, Shaanxi, 710061, China "High Throughput Screening Laboratory, University of Kansas, Lawrence, KS 66047 (USA)

*Correspondence should be addressed to Dr. Shirley ShiDu Yan, 2099 Constant Avenue,

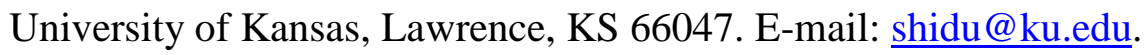




\section{Supporting Information}

\section{Materials and methods}

\section{Synthesis of CypD inhibitors}

Compound C-9 that exhibited the best biological activity based on the measured binding affinities and observed effects on mitochondrial function induced by $\mathrm{Ca}^{2+}$ or $\mathrm{A} \beta_{1-42}$ was used in all pharmacological studies.

A solution of 2-(3-cyano-4-isobutoxyphenyl)-4-methylthiazole-5-carboxylic acid and thionyl chloride was stirred in dry toluene for $30 \mathrm{~min}$ in the presence of a catalytic amount of dimethylformamide to produce an acid chloride intermediate for C-9. Slowly increasing the temperature to $90-95{ }^{\circ} \mathrm{C}$ with constant stirring for $3 \mathrm{~h}$ resulted in a clear solution. The reaction mixture was then cooled slowly to room temperature and concentrated to give a white residue. This residue was dissolved in acetonitrile and an equimolar amount of 4aminobenzenesulfonamide was added. This solution was stirred for $4 \mathrm{~h}$ at $75^{\circ} \mathrm{C}$ to give impure solid $9^{1}$. This solid that was separated by filtration, washed with acetonitrile, ice-cold water, and then recrystallized from ethanol to give pure C-9.

Compound C-9 was present as an off-white powder with a melting point of $297-299{ }^{\circ} \mathrm{C}$, a molecular weight of 471 and a molecular formula of $\mathrm{C}_{22} \mathrm{H}_{22} \mathrm{~N}_{4} \mathrm{O}_{4} \mathrm{~S}_{2}$ (Figure 1). High pressure liquid chromatography (HPLC) purity of compound C-9 was 100\%. HPLC: $100 \%$ at 21.37 min

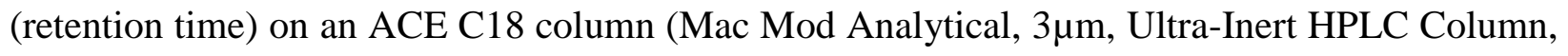
$50 \times 2.1 \mathrm{~mm}$ ) protected by a matched ACE guard cartridge and a detection wavelength of $254 \mathrm{~nm}$. Solvents $\mathrm{A}: \mathrm{H}_{2} \mathrm{O}(99 \%)$, methanol $(1 \%)$ and formic acid $(0.1 \%)$ and $\mathrm{B}: \mathrm{H}_{2} \mathrm{O}(1 \%)$, methanol (99\%) and formic acid $(0.1 \%)$ delivered at a flow rate of $400 \mu 1 / \mathrm{min}$. Using a gradient pump program beginning at $15 \%$ methanol containing $0.1 \%$ formic acid (FA), $\mathrm{H}_{2} \mathrm{O}(1 \%)$, and $85 \%$ aqueous containing $0.1 \% \mathrm{FA}$ and methanol (1\%) with a flow rate of $0.4 \mathrm{~mL} / \mathrm{min}$ for 10 minutes. 


\section{Supporting Information}

The methanol with FA increased linearly from 15 to $80 \%$ from 0.5 to 5 minutes and then was maintained at $80 \%$ from 5 to 45 minutes.

2-(3-Cyano-4-isobutoxyphenyl)-4-methyl-N-(4-sulfamoylphenyl) thiazole-5-carboxamide (C-9): $\mathrm{R}_{f} 0.62$; (methylene dichloride: methanol, 9:1 v/v). ${ }^{1} \mathrm{H}$ NMR (DMSO- $\left.d_{6}\right) \delta: 1.03$ (d, 6H, J $=13.6 \mathrm{~Hz}), 2.12-2.08(\mathrm{~m}, 1 \mathrm{H}), 2.65(\mathrm{~s}, 3 \mathrm{H}), 4.02(\mathrm{~d}, 2 \mathrm{H}, \mathrm{J}=12.4 \mathrm{~Hz}), 7.31(\mathrm{~s}, 2 \mathrm{H}), 7.44-7.40$ $(\mathrm{m}, 1 \mathrm{H}), 8.87-8.81(\mathrm{~m}, 4 \mathrm{H}), 8.25-8.21(\mathrm{~m}, 1 \mathrm{H}), 8.31(\mathrm{~s}, 1 \mathrm{H}), 10.59(\mathrm{~s}, 1 \mathrm{H}) ;{ }^{13} \mathrm{C} \mathrm{NMR}\left(\mathrm{DMSO}-\mathrm{d}_{6}\right)$ $164.4,161.9,160.0,156.2,141.4,139.5,132.9,131.3,126.5,125.8,125.2,119.8,115.3,113.9$, 101.5, 75.0, 27.5, 18.6, 17.1; HRMS cald for $\mathrm{C}_{22} \mathrm{H}_{22} \mathrm{~N}_{4} \mathrm{O}_{4} \mathrm{~S}_{2}(\mathrm{M}+\mathrm{H})+471.1161$; found 471.1164 (TOF MS ES+ ).

\section{Binding experiment of CypD inhibitors with CypD protein}

Surface Plasmon Resonance (SPR) using a BIACORE 3000 at $25^{\circ} \mathrm{C}$ was used to study the binding interaction between compound C-9 and cyclophilin D (CypD). The SPR binding experiments used a dual flow cell as previously described ${ }^{2,3}$. They were conducted in phosphate-

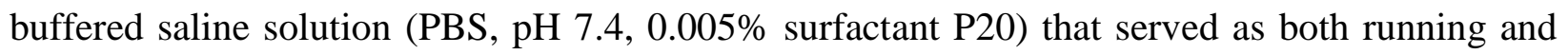
sample buffer. The sensor chip surface was initially activated with mixtures of $\mathrm{N}$ hydroxysuccinimide (NHS, $115 \mathrm{mg} / \mathrm{ml}$ ) and N-(3-dimethyl-aminopropyl)-N'-ethyl-carbodiimidehydrochloride (EDC, $750 \mathrm{mg} / \mathrm{ml}$ ) for $7 \mathrm{~min}$ each. CypD protein was first dissolved in PBS (pH 5.0) at a concentration of $10 \mu \mathrm{g} / \mathrm{ml}$, and then immobilized directly and covalently attached to a hydrophilic carboxy-methylated dextran matrix of the Biacore CM5 sensor chip using the standard primary amine coupling reaction and standard procedures. After the CypD protein was immobilized, the activated carboxylic acid groups were quenched using ethanolamine $(1 \mathrm{M}, \mathrm{pH}$ $8.5)$. 


\section{Supporting Information}

Considerable care was taken to prevent contamination. Samples were carefully injected to avoid carryover effects and the system was carefully washed before injection of each new sample. The sample flow rate was set at $40 \mu \mathrm{l} / \mathrm{min}$ to determine the kinetic and equilibrium constant. The equipment surfaces were washed extensively with buffer solution to restore the surfaces before each binding experiment.

Data analysis was performed using BIA evaluation software. Data analysis and sensor grams were automatic corrected for nonspecific bulk refractive index effects. Standard procedures for the 1:1 Langmuir binding fit model were used for the kinetic analysis of ligand binding to the protein.

\section{Real time fluorescence based CypD Prolyl Isomerase Assay ${ }^{4}$}

Purified recombinant CypD enzyme (10 nM,) diluted in Working Buffer (WB, 25 mM HEPES, $100 \mathrm{mM} \mathrm{NaCl}, 0.01 \%$ Triton $\mathrm{X}-100, \mathrm{pH} 7.5)$ was added to the wells of a 384 well plate containing DMSO vehicle controls or compound 9. Compound 9 was synthesized as previously described and transferred using ECHO 555 (Labcyte) to produce solutions with concentrations ranging from $0.19 \mathrm{uM}$ to $100 \mathrm{uM}(\mathrm{n}=3)$ while keeping the final DMSO concentration less than 0.4\%. The CypD was preincubated with compound 9 at $25^{\circ} \mathrm{C}$ for $1 \mathrm{hr}$. Chymotrypsin ( $\left.25 \mathrm{uM}\right)$ was added to the wells and the pre-reads were captured for 5 seconds before the addition of the substrate (4 uM, Suc-AAPF-MCA in TFE/LiCl Substrate Dilution Buffer). The increase in fluorescence at Excitation /Emission: 340/510 nm was captured every millisecond for a total time of 2 min using Hamamatsu FDSS 7000.

\section{Isolation of brain mitochondria}




\section{Supporting Information}

Brain cortex without white matter from mice was used for mitochondrial isolation. Mitochondria were prepared as formerly described ${ }^{3,5}$. Briefly, brain cortical tissues were homogenized in $9 \mathrm{ml}$ of ice-cold EB buffer (EDTA $1 \mathrm{mmol}$, bovine serum albumin 1-6 mg/ml) using a Dounce homogenizer until particles were no longer seen in the solution. Homogenates were centrifuged at $1300 \mathrm{x} g$ for $5 \mathrm{~min}$. Supernatant from this fraction was carefully deposited on top of $15 \%$ percoll solution $(10 \mathrm{ml})$, and then centrifuged at $16000 \mathrm{RPM}$ for $10 \mathrm{~min}$. Next, the pellet was mixed with $9 \mathrm{ml}$ of mitochondrial buffer (D-mannitol $4.098 \%$, Sucrose $2.56 \%$, $\left.\mathrm{K}_{2} \mathrm{HPO}_{4} 0.034 \%, \mathrm{pH} 7.3-7.4\right)$ and $200 \mu \mathrm{l}$ of $1 \%$ digitonin. After 5 min incubation on ice, the mixture was centrifuged at 8000 RPM for $10 \mathrm{~min}$. Finally, the mitochondrial pellet was resuspended in $100 \mu \mathrm{l}$ of mitochondrial buffer and used for further experiments.

\section{Brain mitochondrial swelling and Calcium uptake/release inhibition assays ${ }^{6}$}

Appropriate amounts of mitochondria were resuspended in $1 \mathrm{ml}$ swelling assay buffer $\left(150 \mathrm{mM} \mathrm{KCl}, 2 \mathrm{mM} \mathrm{KH}{ }_{2} \mathrm{PO}_{4}, 10 \mathrm{mM}\right.$ HEPES, $\mathrm{pH}$ 7.4) and energized with the addition of 1 $\mathrm{mM}$ Glutamate and $1 \mathrm{mM}$ Malate. Calcium $\left(\mathrm{Ca}^{2+}, 200 \mu \mathrm{M}\right)$ was added to the assay buffer to trigger mitochondrial swelling. The mitochondrial permeability transition was determined by measuring the rate of change in absorbance at $540 \mathrm{~nm}$ with an Amersham Biosciences Ultrospec 3100 pro spectrophotometer.

\section{Initial solubilization of $A \beta$ peptide and preparation of oligomer $A \beta$}

$\mathrm{A} \beta_{1-42}$ peptide (lyophilized powder, $1 \mathrm{mg}$, GenicBio, catalog number A-42-T-1) was stored in sealed glass vials inside desiccated containers at $-80{ }^{\circ} \mathrm{C}$. Before resuspension, the lyophilized peptide was allowed to equilibrate to room temperature for $30 \mathrm{~min}$, thereby avoiding condensation. Under a chemical fume hood, the lyophilized $A \beta_{1-42}$ was resuspended in $100 \%$ 1,1,1,3,3,3-hexafluoro-2-propanol (HFIP, Sigma-Aldrich, catalog number 105228) in a 


\section{Supporting Information}

polypropylene vial using a glass GasTight ${ }^{\circledR}$ Hamilton syringe with a Teflon plunger. Following vortexing, the solution was divided between 3 polypropylene vials and vortexed again. The HFIP was allowed to evaporate in the fume hood for 2-3 hour. The resultant pellet was stored in desiccated form at $-20{ }^{\circ} \mathrm{C}$. Directly before use, the aliquots were resuspended in $5 \mathrm{mM}$ anhydrous dimethyl sulfoxide (DMSO, Sigma-Aldrich, catalog number D-2650) by pipette mixing followed by bath sonication for $10 \mathrm{~min}^{3,7}$

\section{Preparation of $A \beta_{1-42}$ Oligomer $^{8}$}

$\mathrm{A} \beta_{1-42}$ oligomers were prepared by diluting $5 \mathrm{mM}$ of $\mathrm{A} \beta_{1-42}$ aliquot in PBS. The solution was immediately mixed by vortexing for $30 \mathrm{sec}$, and incubated at $4{ }^{\circ} \mathrm{C}$ for 24 hours. Prior to the experiment, the aliquot was diluted in ice-cold culture media to the required concentration. As demonstrated in our published studies, we have successfully prepared oligomer $A \beta_{1-42 .}{ }^{3,9-12}$

\section{Culturing of SK-N-SH cells}

The human neuroblastoma-derived cell line SK-N-SH (ATCC HTB-11, American Type Culture Collection, Manassas, VA) was used to assess CypD inhibitor effect on mitochondrial function. The cells were maintained in DMEM media supplemented with $10 \%$ fetal bovine serum in a humidified $37^{\circ} \mathrm{C}, 5 \% \mathrm{CO}_{2}$ incubator.

\section{Measurement of mitochondrial cytochrome c oxidase (CcO) activity}

Cytochrome c oxidase $(\mathrm{CcO})$ activity was measured as described previously ${ }^{3,} 7$ using a cytochrome c oxidase kit (Sigma). Briefly, SK-N-SH cells were incubated with CypD inhibitor 9 and $\mathrm{A} \beta_{1-42}$ oligomer. After incubating at $37{ }^{\circ} \mathrm{C}$ for 48 hours, cells were washed twice with PBS, followed by harvesting of cell lysates. The protein concentration was determined with the 


\section{Supporting Information}

Bradford method. Next, an appropriate volume of cells and enzyme solution was added to $475 \mu 1$ of assay buffer provided with the kit. The reaction was triggered by the addition of $25 \mu$ freshly prepared ferrocytochrome c substrate solution. The rate of change in absorbance at $550 \mathrm{~nm}$ was recorded immediately with Shimadzu (Kyoto, Japan) UV1200 spectrophotometer programmed for a $5 \mathrm{sec}$ delay and $10 \mathrm{sec}$ intervals for a total of six readings.

\section{Measurement of adenosine-5'-triphosphate (ATP) levels}

ATP levels were evaluated using an ATP Bioluminescence Assay Kit (Roche) as was formerly described $^{3,13}$. In brief, SK-N-SH cells were incubated with CypD inhibitor C-9 and $\mathrm{A} \beta_{1-42}$ oligomer at $37{ }^{\circ} \mathrm{C}$ for 48 hours. Next, cells were harvested using ATP lysis buffer followed by incubation for $15 \mathrm{~min}$ on ice. The mixture was centrifuged at $13,000 \times \mathrm{g}$ for $10 \mathrm{~min}$ at $4^{\circ} \mathrm{C}$, and the supernatant was collected for the assay. The content of ATP levels were measured using a Luminescence plate reader (Molecular Devices) with an integration time of 10 $\mathrm{s}^{3,7}$. Essentially, light emitted from the luciferase-mediated reaction was captured by a luminescence plate reader (Molecular Devices) at $37^{\circ} \mathrm{C}$ with an integration time of $10 \mathrm{sec}$.

\section{Cell survival and toxicity assay}

The MTT (3-(4,5-dimethylthiazol-2-yl)-2,5-diphenyltetrazolium_bromide) assay is commonly used to examine cell proliferation for the overall assessment of cell viability. SK-NSH cells were treated with a range of CypD compound C-9 (at $0,5,10,25,50$, and $100 \mu \mathrm{M}$ ) for 48 hours and then analyzed using the MTT reduction assay following the manufacturer's instructions. Each experiment was run three times. 
Supporting Information

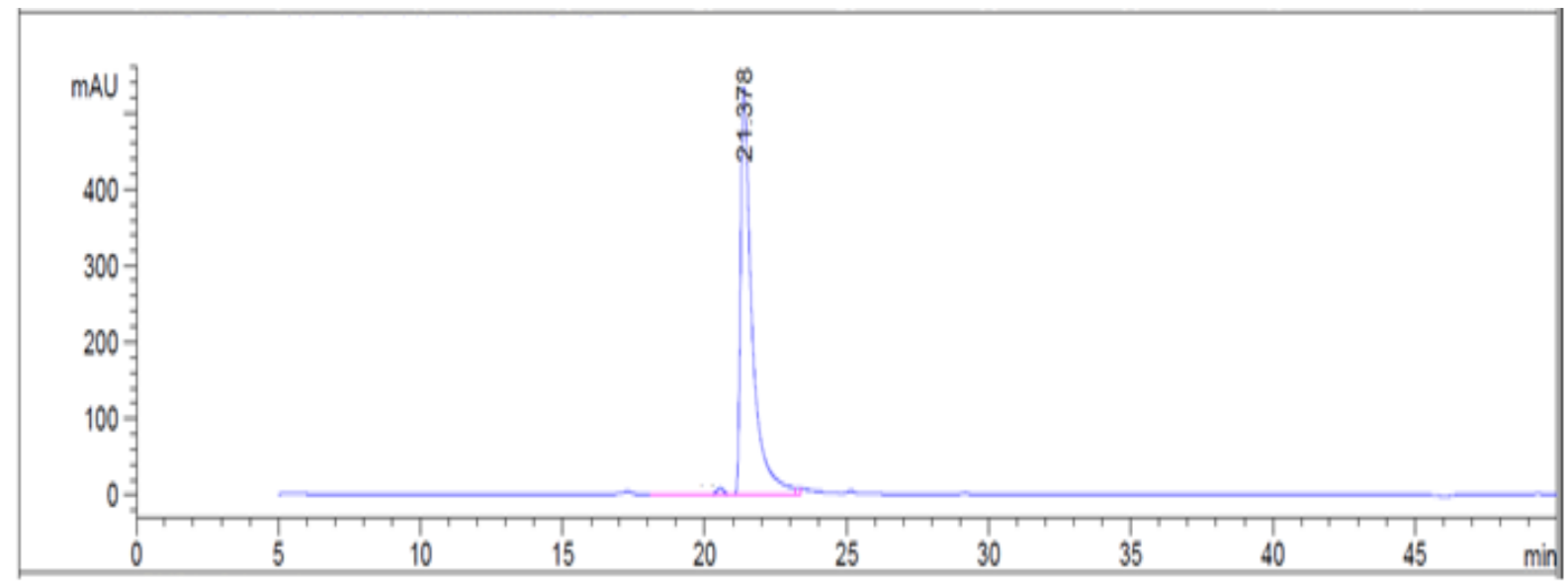

Figure 1: HPLC Chromatogram for compound C-9

\begin{tabular}{|c|c|c|c|c|c|}
\hline $\begin{array}{c}\text { Peak } \\
\#\end{array}$ & $\begin{array}{l}\text { Ret Time } \\
\text { [min] }\end{array}$ & $\begin{array}{l}\text { Width } \\
\text { [min] }\end{array}$ & $\begin{array}{c}\text { Area } \\
{\left[\mathrm{Mau}^{*} \mathrm{~s}\right]}\end{array}$ & Height & $\begin{array}{c}\text { Area } \\
\%\end{array}$ \\
\hline 1 & 21.376 & 0.5368 & $7.11374 \mathrm{e} 4$ & 2208.65479 & 100.00 \\
\hline \multicolumn{3}{|c|}{ Total: } & $7.11374 \mathrm{e} 4$ & 2208.65479 & \\
\hline
\end{tabular}




\section{Supporting Information}

\section{Reference:}

1. Valasani, K. R.; Vangavaragu, J. R.; Day, V. W.; Yan, S. S. Structure Based Design, Synthesis, Pharmacophore Modeling, Virtual Screening, and Molecular Docking Studies for Identification of Novel Cyclophilin D Inhibitors. J Chem Inf Model. 2014, 54, 902-912.

2. $\quad$ Lustbader, J. W.; Cirilli, M.; Lin, C.; Xu, H. W.; Takuma, K.; Wang, N.; Caspersen, C.; Chen, X.; Pollak, S.; Chaney, M.; Trinchese, F.; Liu, S.; Gunn-Moore, F.; Lue, L. F.; Walker, D. G.; Kuppusamy, P.; Zewier, Z. L.; Arancio, O.; Stern, D.; Yan, S. S.; Wu, H. ABAD Directly Links Abeta to Mitochondrial Toxicity in Alzheimer's Disease. Science 2004, 304, 448-452.

3. Du, H.; Guo, L.; Fang, F.; Chen, D.; Sosunov, A. A.; McKhann, G. M.; Yan, Y.; Wang, C.; Zhang, H.; Molkentin, J. D.; Gunn-Moore, F. J.; Vonsattel, J. P.; Arancio, O.; Chen, J. X.; Yan, S. D. Cyclophilin D Deficiency Attenuates Mitochondrial and Neuronal Perturbation and Ameliorates Learning and Memory in Alzheimer's Disease. Nat. Med. 2008, 14, 1097-1105.

4. $\quad$ Mori, T.; Itami, S.; Yanagi, T.; Tatara, Y.; Takamiya, M.; Uchida, T. Use of a Real-Time Fluorescence Monitoring System for High-Throughput Screening for Prolyl Isomerase Inhibitors. J Biomol Screen 2009, 14, 419-424.

5. $\quad$ Caspersen, C.; Wang, N.; Yao, J.; Sosunov, A.; Chen, X.; Lustbader, J. W.; Xu, H. W.; Stern, D.; McKhann, G.; Yan, S. D. Mitochondrial Abeta: a Potential Focal Point for Neuronal Metabolic Dysfunction in Alzheimer's Disease. FASEB J. 2005, 19, 2040-2041.

6. Valasani, K. R.; Sun, Q. R.; Hu, G.; Li, J. P.; Du, F.; Guo, Y. P.; Carlson, E. A.; Gan, X. Q.; Yan, S. S. Identification of Human ABAD Inhibitors for Rescuing A beta-Mediated Mitochondrial Dysfunction. Curr Alzheimer Res. 2014, 11, 128-136.

7. Du, H.; Guo, L.; Yan, S.; Sosunov, A. A.; McKhann, G. M.; Yan, S. S. Early Deficits in Synaptic Mitochondria in an Alzheimer's Disease Mouse Model. Proc Natl Acad Sci U S A. 2010, 107, 18670-18675.

8. Stine, W. B., Jr.; Dahlgren, K. N.; Krafft, G. A.; LaDu, M. J. In Vitro Characterization of Conditions for Amyloid-Beta Peptide Oligomerization and Fibrillogenesis. J Biol Chem. 2003, $278,11612-11622$.

9. Du, H.; Guo, L.; Wu, X.; Sosunov, A. A.; McKhann, G. M.; Chen, J. X.; Yan, S. S. Cyclophilin D Deficiency Rescues Abeta-Impaired PKA/CREB Signaling and Alleviates Synaptic Degeneration. Biochim Biophys Acta 2013, 1842, 2517-2527.

10. Du, H.; Guo, L.; Yan, S. S. Synaptic Mitochondrial Pathology in Alzheimer's Disease. Antioxid Redox Signal. 2013, 15, 1467-1475.

11. Guo, L.; Du, H.; Yan, S.; Wu, X.; McKhann, G. M.; Chen, J. X.; Yan, S. S. Cyclophilin D Deficiency Rescues Axonal Mitochondrial Transport in Alzheimer's Neurons. PLoS One 2013, 8 , e54914.

12. Origlia, N.; Bonadonna, C.; Rosellini, A.; Leznik, E.; Arancio, O.; Yan, S. S.; Domenici, L. Microglial Receptor for Advanced Glycation End Product-Dependent Signal Pathway Drives Beta-Amyloid-Induced Synaptic Depression and Long-Term Depression Impairment in Entorhinal Cortex. J Neurosci 2010, 30, 11414-114125.

13. Yao, J.; Du, H.; Yan, S.; Fang, F.; Wang, C.; Lue, L. F.; Guo, L.; Chen, D.; Stern, D. M.; Gunn Moore, F. J.; Xi Chen, J.; Arancio, O.; Yan, S. S. Inhibition of Amyloid-beta (Abeta) Peptide-Binding Alcohol Dehydrogenase-Abeta Interaction Reduces Abeta Accumulation and Improves Mitochondrial Function in a Mouse Model of Alzheimer's Disease. J Neurosci. 2011, 31, 2313-2320. 